\title{
Green Roofs Towards Circular and Resilient Cities
}

\author{
Cristina S. C. Calheiros ${ }^{1}$ (D) $\cdot$ Alexandros I. Stefanakis $^{2}$ (D)
}

Received: 9 February 2021 / Accepted: 16 March 2021 / Published online: 26 March 2021

(C) The Author(s), under exclusive licence to Springer Nature Switzerland AG 2021

\begin{abstract}
Green roofs are gaining interest as nature-based solutions (NBS) to counteract with several environmental and socio-economic problems associated to urban sprawl and climate change. The challenge is to transform the built environment through the inclusion of NBS. Taking advantage of the existing space in the top of the buildings, the integration of green roofs will support the cities' transition towards circularity and resilience. They provide several ecosystem services and can act as multifunctional and decentralized units. In order to boost these services, green roofs need to be effectively incorporated and replicated in the urban landscape. Different configuration of systems may be considered depending on the challenges that the city foresees. To fully implement green roofs, it is important that (i) barriers are identified and overcome, (ii) standardization is set to grant liability, (iii) policies, incentives, and strategies are properly established, (iv) organizations delivering NBS services are leveraged, and (v) awareness and dissemination promotion, as investment in education, are considered. This paper intends to give an overview of the importance of green roof integration in the urban environment considering the dimensions of the building and the city, having underlined their contribution to circularity and cities' resilience.
\end{abstract}

Keywords Nature-based solutions · Ecosystem services · Circular economy · Roof gardens · Urbanization · Sustainable development

\section{Introduction}

Urban settlements are of great importance in the context of global development since they house $55 \%$ of the world's population, being projected by 2050 an increase to $68 \%$ [1]. The

Cristina S. C. Calheiros

cristina@calheiros.org

1 Interdisciplinary Centre of Marine and Environmental Research (CIIMAR/CIMAR), University of Porto, Novo Edifício do Terminal de Cruzeiros do Porto de Leixões, Avenida General Norton de Matos, S/N 4450-208, Matosinhos, Portugal

2 School of Environmental Engineering, Technical University of Crete, GR73100 Chania, Greece 
urban settlements include cities, towns, and suburbs, and are intimately connected with surrounding rural areas. The well-being of future generations in cities will be dictated in part by the level of urbanization that they precede [2]. Urbanization is closely related with the spatial distribution of the world's population, being one of the four demographic mega trends, i.e., growth of the global population, population aging, and international migration [1]. For instance, while population is expected to continue to grow exponentially across most of the globe, this is less seen in Europe [2].

The sustainable development of urban settlements depends increasingly on the successful management of their growth, in order to maximize the benefits for the agglomeration while minimizing the environmental degradation and other potential adverse impacts [1]. This must be achieved in order to lessen the environmental pressure beyond the city boundaries concerning water and energy provision, and food security, among other services, for urban populations [2]. Urban sprawl may lead to, but not limited to, increased soil impermeability, changes in hydraulic regimes and nutrient availability, increases in abiotic stressors (e.g., air pollution), habitat fragmentation, and biodiversity and ecosystem service loss [3, 4], since other social and economic repercussion may be sparked.

A transformation of the urban systems is needed to address the actual challenges and involve decision-makers, municipalities, businesses, other stakeholders, and society. For example, the Driving Urban Transitions Towards a Sustainable Future (DUT) partnership addresses a set of urban challenges through an integrated approach, joining research, innovation, and actions, in order to build capacities to support the urban transition. Further on, it intends to contribute to boosting the impact of global policies related to the United Nations (UN) Agenda 2030, the Green Deal, The Paris Agreement, and the Urban Agenda for the European Union (EU). Four priority themes have been identified of needing of action to support urban transitions: (i) digital transitions in urban governance, (ii) from urban resilience to robustness, (iii) sustainable land-use and urban infrastructures, and (iv) inclusive public spaces. From these themes, sectorial priorities were established concerning (i) urban energy transitions through positive energy districts, (ii) urban mobility transitions through accessibility and connectivity, and (iii) urban greening through nature-based solutions (NBS) and circular economies [5]. Another example is the recently launched New European Bauhaus initiative that "is an environmental, economic and cultural project, aiming to combine design, sustainability, accessibility, affordability and investment in order to help deliver the European Green Deal." The core values are sustainability, esthetics, and inclusiveness that support an innovative co-design process to find solutions for actual problems and concerns, through a multisectoral participatory approach [6].

Achieving inclusive, safe, resilient, and sustainable cities is a global goal. The importance of urban resilience has been specifically emphasized by ICLEI [7] as "the ability of cities to anticipate, prevent, absorb and recover from shocks and stresses, and to improve essential basic response structures and functions, while integrating the different aspects of urbanization, sustainability, development, and climate change." This concept, associated to the transition towards a circular economy, strengthens the mentioned global goal. It has also been referred by Noll [5] in relation to the European Partnership, under Horizon DUT, that the "circular in cities involves the pattern by which resources and materials are shared and transported" as waste is no longer considered disposable but rather as a resource. Having that in consideration, there is a close linkage between mobility, infrastructures, and land use. Gravagnuolo et al. [8] highlighted the main criteria and indicators towards a circular city assessment framework, underlining the existence of an open field of research related to the urban metabolism 
assessment and circular cities. The term urban metabolism is a concept in which "the city is analyzed using the biological notion referring to the internal processes by which living organisms maintain a continuous exchange of matter and energy with their environment to enable operation, growth and reproduction" [9]. A sustainable built environment is, thus, supported by cycles and their synergies, where the flow of resources and materials is dynamic and has to be considered in the planning processes in cities and translated in the understanding of urban metabolism.

When addressing specifically the built environment, where re-construction or retrofit is usually preferable in detriment of new constructions, challenges still pose on the reuse of building materials when evaluating the environmental benefits and impacts on logistics and transportation [5]. This aspect is of special interest since the building-construction sector in cities is one of the most rapidly developing in relation to circular economy, thus being a key sector of investment. Nevertheless, there is a need to pave the way concerning the optimization of the end-of-life of buildings materials considering the establishment of a remanufacturing and refurbishing cycling of products and components. In this aspect, there is still a long way to go in order to consider the whole supply chain of building components in a circular approach that entails cities' regeneration $[8,10]$.

A way to approach the actual cities' challenges is to introduce NBS in the urban landscape. Including NBS in the built environment can contribute to a circular economy and, through the provision of ecosystem services, can counteract the negative impacts of urbanization and climate change mitigation and adaptation. This can occur at three different levels: (i) green building materials, (ii) green building systems, and (iii) green building sites [11]. In this context, green roofs are an example of NBS that can be implemented at a building scale, facing different challenges when applied in new or existing buildings. This paper aims at giving an overview of the approaches to integrate green roofs as NBS concepts in cities and of their main contributions towards circularity and resilience of the built environment. The analysis highlights the green roofs framework and underlying concepts, as well as the way to integrate them and the services they deliver in the urban environment. Furthermore, their role is emphasized towards circular and resilient cities.

\section{Methodology}

\section{Theoretical Framework and Review Rationale}

This comprehensive literature review was based upon peer-reviewed journal articles, guidelines, manuals, books, and websites that supported a holistic approach to address the different dimensions of green roofs and their relevance towards circular and resilient cities. The following research questions were used to guide this literature review:

What are the concepts underlying the green roofs technology?

How can green roofs be integrated in urban planning?

What are the main drivers to enable and promote the green roofs in cities?

Considering the abovementioned research questions, the present review was structured as follows: 
- The framework concerning the integration of NBS and green infrastructures in cities was examined, with emphasis on green roofs, based on UN and EU trends (the "Nature-Based Solutions in Cities: Green Roofs" section).

- The typologies of green roofs were characterized based on guidelines and review approaches (the "Build-up Engineered Ecosystems" section).

- The contribution of green roofs to cities was reviewed, taken in consideration the buildings retrofitting, the ecosystem services delivered, and the nexus of Water-Energy-MaterialsFood-Ecosystem that they comprise (the "Green Roofs Contribution to the Cities" section).

- The main considerations were highlighted based on the review carried out underpinning the relevance of green roofs to circularity and cities resilience (the "Conclusions" section).

\section{Nature-Based Solutions in Cities: Green Roofs}

Cities' engagement towards sustainability is supported by the New Urban Agenda and the 2030 Sustainable Development Goals [2]. It is envisaged by the New Agenda that cities and human settlements will "Protect, conserve, restore and promote their ecosystems, water, natural habitats and biodiversity, minimize their environmental impact and change to sustainable consumption and production patterns" [12]. Emphasizing the threats to biodiversity loss and ecosystem services decay, McDonald et al. [13] proposed to counteract these trends by (1) considering ecosystem services as an urban utility so cities can structure their governance and urban planning processes accordingly, (2) establishing efforts, such as local-level solutions, to protect specific biodiversity hotspots under urbanization pressure, and (3) promoting international collaboration and coordination towards urban sustainability. For that, the integration of NBS and green infrastructures (GI) in cities is of outmost importance towards re-naturing cities and territorial resilience [14], in accordance with the EU Research and Innovation policy agenda [15]. Moreover, the pivotal role of NBS has been acknowledged as a fundamental part of action for climate and biodiversity as widely supported by the manifesto from the UN Climate Action Summit [16] and the EU Green Deal [17]. Research networks are being established to address these issues, as the COST Actions, that promote collaboration among scientists across Europe, and beyond, catalyzing research advancements and innovation. For example, the EU-funded COST Action CA17133 deals with Circular City "Implementing nature-based solutions for creating a resourceful circular city" (https://circular-city.eu; [18]).

NBS may be considered "solutions that are inspired and supported by nature, which are cost-effective, simultaneously provide environmental, social and economic benefits and help build resilience" [14]. Further on, they can integrate a GI that is "a strategically planned network of natural and semi-natural areas with other environmental features designed and managed to deliver a wide range of ecosystem services" [19]. A GI-led design approach would meet the cities' needs towards the establishment of a network of healthy and attractive new and retrofitted environments, allowing the linkage between the existence GI and strengthen the city resilience to urban pressures $[14,20,21]$. Also, the Sponge City concept, that is already in action, promotes these ideas, as the intention is to establish "an urban environment that is devoted to finding ecologically suitable alternatives to transform urban infrastructures into green infrastructures so these could capture, control and reuse precipitation in a useful, ecologically sound way" [22].

Green roofs are considered an example of NBS that provide ecosystem services and functions to different extents $[23,24]$. When they are incorporated and replicated in the city, 
together with other NBS, as decentralized systems, the effect of their services and functions is boosted. The opportunity to spark a transformation in the cities is to consider them as a living organism [9]. Therefore, in order to have an integrated approach with a holistic view, the interactions between the green and grey infrastructures should be considered. It is envisaged that green solutions are disseminated in, on, and around the buildings, at different scales (building, neighborhood, and city). Furthermore, the urban landscape will fit for the future when combining biology and technology towards human well-being and safety and consider the territories as a continuum of fluxes (Fig. 1). Buildings with this approach are no longer static city elements, but instead are dynamic and interactive elements with their surroundings and inhabitants.

Although green roofs have a long history, only recently, they have been considered engineered ecosystems, designed based on scientific knowledge and supported in technical guidelines and standards. They are by definition systems that are installed on a constructed structure and comprise vegetation planted over a substrate followed by different layers, depending on the type of green roof [23, 25-27].

\section{Build-up Engineered Ecosystems}

As mentioned above, green roofs are NBS, also known as vegetated roofs, eco-roofs, or living roofs, that comprise an engineered system with different layers. These systems include flows of energy, water, nutrients, and very specific organisms that are not normally quantified and are not properly valued [25, 27]. They can be classified, according to standard guidelines [28], as being intensive, semi-intensive, and extensive, depending on their structural composition and maintenance specifications (Table 1; Fig. 2).

In intensive green roofs, it is possible to find a wide variety of plant species, from grasses and small shrubs to trees, supported on substrate thicknesses normally greater than $25 \mathrm{~cm}$, although the topography will vary according to the design. Maintenance needs are identical to a garden with respect to fertilization, irrigation, and plant accommodation. They are accessible to the public, performing functions of leisure areas and social interaction. The implementation and maintenance costs are higher when compared to an extensive green roof. On the other hand, extensive green roofs are characterized by plant species, such, herbs, grasses, aromatic

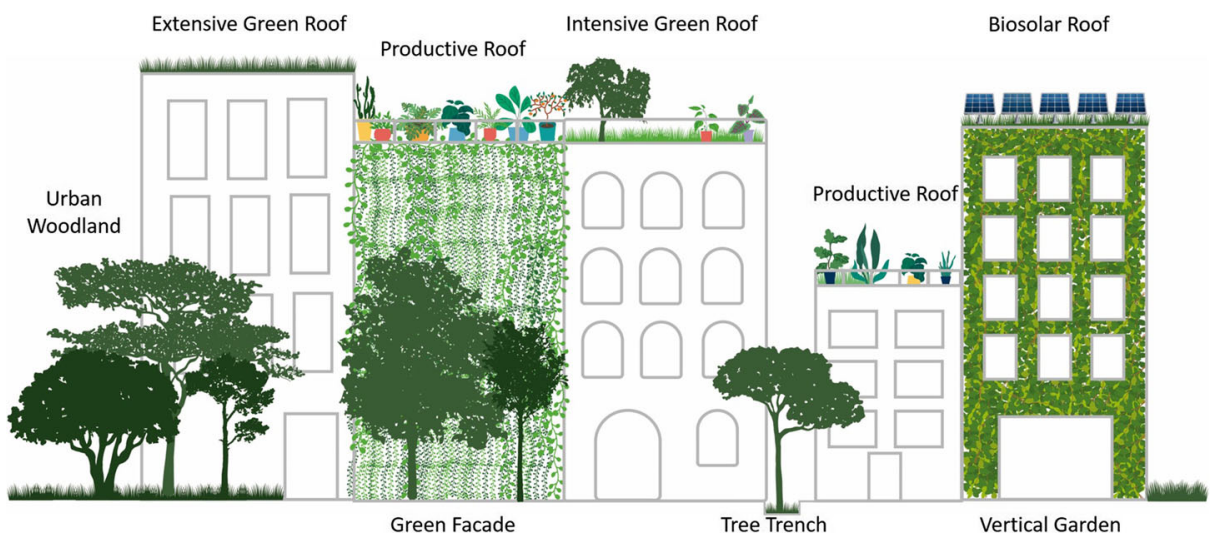

Fig. 1 Integration of nature-based solutions in the built environment 
Table 1 Comparison between the different classifications of green roofs (adapted from [29])

\begin{tabular}{llll}
\hline Criteria & \multicolumn{2}{l}{ Types of green roofs } & \\
\cline { 2 - 4 } & Intensive green roof & $\begin{array}{l}\text { Semi-intensive green } \\
\text { roof }\end{array}$ & Extensive green roof \\
\hline Maintenance & High & Periodic $/$ moderate & Low \\
Substrate layer & $>25 \mathrm{~cm}$ & $15-25 \mathrm{~cm}$ & $8-15 \mathrm{~cm}$ \\
Vegetation & Trees, shrubs, lawn & $\begin{array}{l}\text { Grass-herbs, shrubs } \\
150-350 \mathrm{~kg} / \mathrm{m}^{2}\end{array}$ & $\begin{array}{l}\text { Succulent }(\mathrm{sedum}), \text { mosses, grass } \\
80-180 \mathrm{~kg} / \mathrm{m}^{2} \\
\text { Weight of the }\end{array}$ \\
$\begin{array}{c}\text { system } \\
\text { Accessibility }\end{array}$ & $\begin{array}{l}\left(350 \mathrm{~kg} / \mathrm{m}^{2}\right. \\
\text { In general, without }\end{array}$ & $\begin{array}{l}\left(1.47-3.43 \mathrm{kN} / \mathrm{m}^{2}\right) \\
\text { Limited stepping }\end{array}$ & $\begin{array}{l}\text { No stepping, unless for } \\
\text { maintenance }\end{array}$ \\
\hline
\end{tabular}

plants, mosses, and succulents (such as Sedum), set on a substrate layer of 8-15-cm thickness. They require low maintenance as low watering input. They are usually not accessible to the public. Concerning the costs of implementation and maintenance, these are much lower when compared to the other categories. Finally, semi-intensive green roofs are characterized by small plants such as shrubs and grass, supported by a layer of substrate typically varying between 15 and $25 \mathrm{~cm}$. They are able to perform multiple functions, with areas of gardens and the possibility of public access. They require less maintenance than intensive ones, although it should be performed on a regular basis [25, 29].

Other types of green roofs are also widely applied, such as the biosolar roof; the major advantage of which is to provide renewable energy through photovoltaic panels, in combination with the other benefits provided by the plants and subsequent generated ecosystem. The vegetation allows additional performance benefits for the panels [30, 31]. The blue-green roofs are another variation, wherein a roof structure vegetation is combined with elements of stormwater management, in order to promote the increase of both volume of stored water and amount of water release [32]. The biodiverse roofs are designed to house a higher biodiversity, in terms of fauna and flora, than the conventional categories of green roofs. They comprise different substrate thicknesses and may have structural elements to provide habitat and shelter for different species [33]. Cities like Toronto created their own guidelines for promotion of this type of green roof [34]. Brown roofs were initially thought as a selfcolonization spot, where seeds would be brought, through the wind and birds, and were left as in a brownfield. The substrate was based on crushed concrete. The promoters of this concept

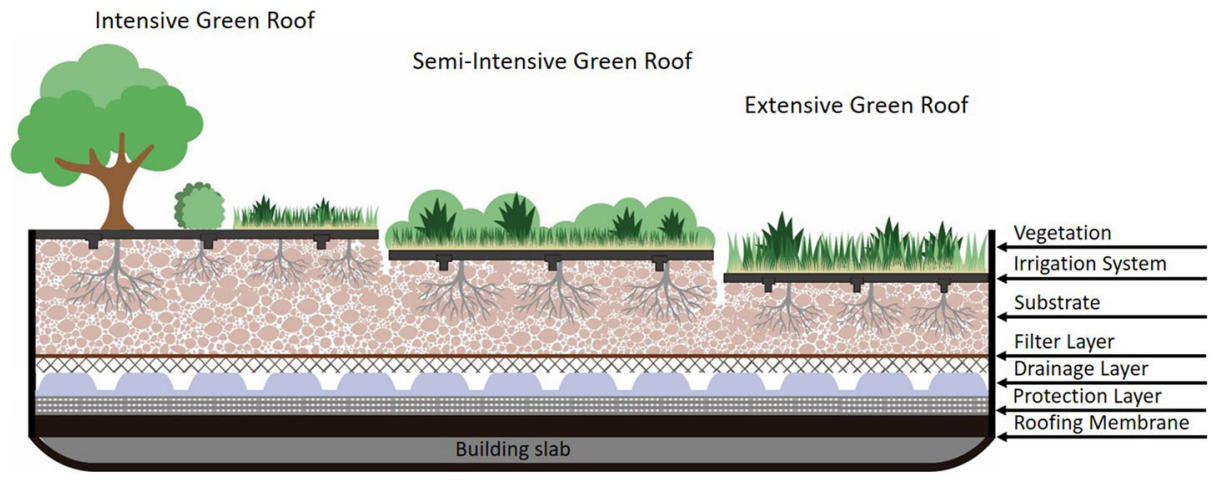

Fig. 2 Typical green roof cross-sectional layers and classification (not to scale) 
have now put it aside due to its poor value in terms of storing and providing water, besides the unwanted vegetation that may appear and it can either give the impression of an unkempt system or it can damage the roof (https://livingroofs.org/biodiversity-and-wildlife). The use of rooftops for urban agriculture (productive green roofs) is also gaining interest to facilitate local agricultural sustainability in urban areas, besides other social-economic benefits [35].

The components that in general integrate a green roof are those that set on the constructed structure, already waterproofed; some of these components may coincide with the same product and have different positions. Main components that integrate a green roof system are vegetation, substrate, irrigation system (specially for regions with long dry periods), filter layer, drainage layer, protection layer, and roofing membranes, resting on an insulated structure (Fig. 2) [23, 28]. These components typically exist on multilayer green roofs, some of which can be omitted on classic green roofs, such as the filter layer. Also, it can be considered an inverted roof, also referred to as "upside down" roof, that is characterized by a reverse arrangement of certain layers. This means that the thermal insulation layer is above the waterproofing, meaning that the waterproofing is applied directly onto the load-bearing roof structure. It is important to acknowledge the functions and purposes of each layer in order to properly design the green roof and meet the expectations. The local climatic conditions must also be taken in consideration to achieve the optimum results. The phase of green roof concept is crucial to have a cost-effective system, with selected materials following a circular approach that have an adequate weight for the building in question. Briefly, the main layers comprising a green roof are $[23,28]$ :

- Vegetation: It is considered the first (top) layer of the roof, set on a technical substrate. The selection of plant species should consider the type of green roof envisaged, the ecosystem services that should be provided, the climatic conditions, and the irrigation requirements. The plants are the most visible part of the green roof and act as an important indicator of the health and operational status of the system. Further on, plants have an important role in relation to biodiversity promotion below and above the ground (rooting system), besides providing protection against substrate erosion and reflecting part of the solar radiation.

- Irrigation system: this component is of outmost importance, especially when facing with the unpredictability of climate change and in regions where long periods without precipitation are expected. An irrigation plan may be outlined, although the use of water should be kept to a minimum and when strictly necessary, aiming at a proper and efficient water management. During the plant rooting phase, more water input is usually required, while afterwards the water demand decreases dramatically.

- Substrate or technical media: the substrate acts as the support for plants and houses the biodiversity (microfauna and macrofauna) associated to the green roof system. Provides also water and nutrients. The substrate characteristics will vary according to the green roof design and technical specifications established for an efficient system operation, namely regarding water storage and drainage, thermal insulation, and proper conditions for plant development. Usually, a technical/commercial substrate provided by a certified supplier is adequate for this purpose, being tailor-made for green roof application, with performance guarantee. They are special mixtures of light materials, composed mainly of mineral components, with an organic content adequate to either extensive or intensive categories. The use of soil is not suitable, in general, due to problems related with compaction; hydraulics constraints; clog of the filter layer; and presence of propagules, seeds, or parts of weed species with high maintenance costs to control. Soil can be used in some cases, 
when the intensive green roof is setup according to the classic model, but still with high restrictions and following the standard guidelines (https:/www.greenroofs.pt/en/faq accessed on: 28/01/21).

- Filter layer: also known as a filter sheet or separation layer, geotextile-based, is manly designed to prevent substrate particles of being washed into the drainage layer and consequently clog it.

- Drainage layer: This layer follows the filter membrane and intends to drain the excess water from the substrate so it does not get waterlogged. That way, it prevents the substrate from becoming saturated, keeping humidity stable, and contributing to sustaining a healthy microfauna population. This layer often is made of high-density polyethylene (HDPE), polystyrene, or lightweight expanded clay. There has been an effort to bring to the market more ecological solutions, such as the one made of waste generated by collecting and subsequently processing cork, insulation cork board (ICB) (technical panel GUL - green urban living), having shown the potential to replace the polyolefin reference product [36].

- Protection layer: this layer protects against mechanical damage acting as waterproofing and insulation of the green roof, usually made of polyurethane and rubber. On inverted roofs, the protection layer is made by extruded polystyrene (XPS) that is installed because of the thermal insulation.

- Roofing membrane: this membrane sets the physical separation between the layer above and the structural supports below. If a specific layer has not been introduced before, in the upper layers, it can act as an impermeable membrane with anti-root characteristics.

\section{Green Roofs Contribution to the Cities}

\section{Retrofitting: Long Live the Roof}

Green roofs can be a solution that triggers a shift in urban context concerning the use of available space in the top of the buildings, since 40 to $50 \%$ of the impermeable surface area, in most developed cities, is attributed to the roofs [37]. The retrofitting of existing buildings with green roofs is of paramount importance, not only to counteract with the impermeability negative effects but also because they are also responsible, to a certain extent, for carbon emissions. For instance, $45 \%$ of all carbon emissions in the UK come from existing buildings (e.g., appliances, heating), and it is predicted that $87 \%$ of all those buildings will still be operational in 2050 [38]. The environmental impacts can be reduced by between 1.0 and $5.3 \%$ if a common flat roof is replaced by a green roof [39]. The retrofitting of buildings with green roofs can thus be seen as a way to reduce the carbon footprint, the environmental impact of the built environment, and the climate change effects.

Not all buildings are suitable for retrofitting; of special concern are the historical buildings which are required to go through a thorough evaluation [40]. It is important to consider in new buildings the inclusion of green roofs already in the design stage, so that their structural integrity is taken in account. Recently, the development of more sustainable green roofs gains interest, that encompass a different design solution, with a careful selection of the build-up materials and components towards a circular economy, since green products/materials are not inherently sustainable. For this, materials should be locally supplied (in terms of their origin and supplier company), if possible, to be reused, recycled, or compatible to biological cycles, with the least embedded non-renewable energy, assuring durability and meeting the standard 
requirements for structural integrity of the system [12]. Products/materials should be designed and conceived differently if a pad to circularity is taken. The promotion of circularity principles throughout the lifecycle of buildings is thus embedded in the Circular Economy Action Plan, when referring to the key product value chains of construction and buildings, and envisaged in the new comprehensive Strategy for a Sustainable Built Environment [41]. The role of green roofs in the urban Water-Energy-Food-Ecosystem nexus has been addressed [42], but is of most importance to consider another component, i.e., the materials. The nexus of Water-Energy-Materials-Food-Ecosystem fosters the relevance of circular economy associated to the building materials and their life expectancy and end-of-life use.

In general, green roofs have longer lifetime than conventional/exposed roofs due to the reduction of exposure of the roof membrane. The green roof system can thus protect the membrane (i) from mechanical damage (e.g., direct stepping and dirt), (ii) from solar radiation (e.g., as much as $87 \%$ can be shield of solar radiation while a conventional roof receives $100 \%$ direct exposure), and (iii) by buffering the temperature extremes during the day (minimizing the damage of daily expansion and contraction of the roof materials) [43, 44]. The green roof life span in countries with technical standards for their construction is expected to have the same duration with the building's waterproofing (30 to 40 years). They may have an expected increase of life span up to 40 years when compared to conventional roofs (20 years). This leads also to less frequent roof replacements and less intensive operational actions during the building's life, consequently reducing the future maintenance and associated costs [40, 44]. For example, Berlin is a city with green roofs reaching approximately 100 years in age [45].

When considering a roof building retrofit, it is critical to assess the building structural bearing capacity in order to evaluate what type of green roof can be accommodated or not. The load-bearing capacity of the roof structure together with the structural capacity of the building and its age will determine the type of vegetation, substrate depth, and construction methods to be adopted [39]. According to Wilkinson and Dixon [40], structural and physical suitability of a green roof retrofit must consider (1) roof structure and covering typologies, (2) available space, (3) structural capacity, (4) waterproofing membranes and insulation, (5) drainage, (6) heritage, (7) green roof access, (8) how to determine which green roof type is best suited to different structures, and (10) access for maintenance.

\section{Green Roofs Beyond Esthetics}

As manmade systems, green roofs cannot be mistaken as natural, but once established, they develop interconnections and gain life of their own. At a first glance, the green roofs esthetic potential may be perceived to what one might experience looking upon any garden, although this is limited and not representing the total esthetic benefits of green roofs [24]. Sutton [24] emphasized three categories of beauty: enjoyable beauty, admirable beauty, and ecological beauty, whereas even ecological esthetic guidelines applied to green roofs have also been proposed. An ecological approach to beauty goes beyond the superficial characteristics and emerges in "unseen forms and processes, deeply and holistically engaging our personal experience." The green roof esthetic element is the most intangible benefit, although it is relevant to engage the client/user not just for the visual component but to educate him/her about the nature dynamics, ecological dimension, and roof metamorphoses, while awakening other human senses [24].

A green roof, besides having a relevant esthetic component in terms of human visual perception, should also be integrated in the landscape, especially in city centers and where 
historical buildings need to be taken into consideration. When addressing intensive green roofs, the connection to leisure areas is an invitation to connect with nature within the built environment (Fig. 3).

Beyond esthetics, green roof provides an array of benefits and ecosystem services that can be briefly summarized in stormwater retention to reduce peak flow and runoff, water quality improvement for water utilization, thermal benefits to improve the microclimate and reduce the energy costs within the buildings, urban heat island effect mitigation, air cleaning for easy comfort in urban areas, and ecological and socio-economic benefits [26, 29]. Green roofs are also being increasingly considered for urban food production, especially after the recent novel coronavirus 2019 (COVID-19) pandemic crisis that led cities to think about the population demand for food, the dependence on imports, and the impact of unpredicted food supply chains disruptions [46].

\section{Green Roofs as Integrated Solutions}

Green roofs are integrated solutions combining the existing knowledge, empowering multiple functions, and providing a panoply of ecosystem services. Green roofs system conception may fit on the permaculture basis that intends to be "a system of assembling conceptual, material, and strategical components in a pattern which functions to benefit life in all its forms" [47]. Permaculture strategies focus on the opportunities, rather than the obstacles, following the dynamics of natural systems and mimic features to achieve higher resilience, sustainability, and productivity. For that, working with nature rather against it is a permaculture's intrinsic principle. The observation of natural systems is the inspirational platform for the creation of regenerative systems, where each element plays many functions. The core of permacultures is design. When designing for a site, the following components should be taken into consideration: site components (e.g., water, earth, landscape, climate, plants), energy components (e.g., technologies, structures, sources, connections), social components (e.g., legal aids, people, culture, trade, and finance), and abstract components (e.g., timing, data, ethics) [47].

Mollison and Slay [48] enumerated the design principles in permaculture that embrace various disciplines and can be used as a tool to combine all separated parts of the design into a functional and synergistic system. These principles are applied when making decisions about the landscape at different scales:

- Relative location: the location of every element (e.g., house, pond) is considered in relation to how they can assist each other. This approach highlights the connection between
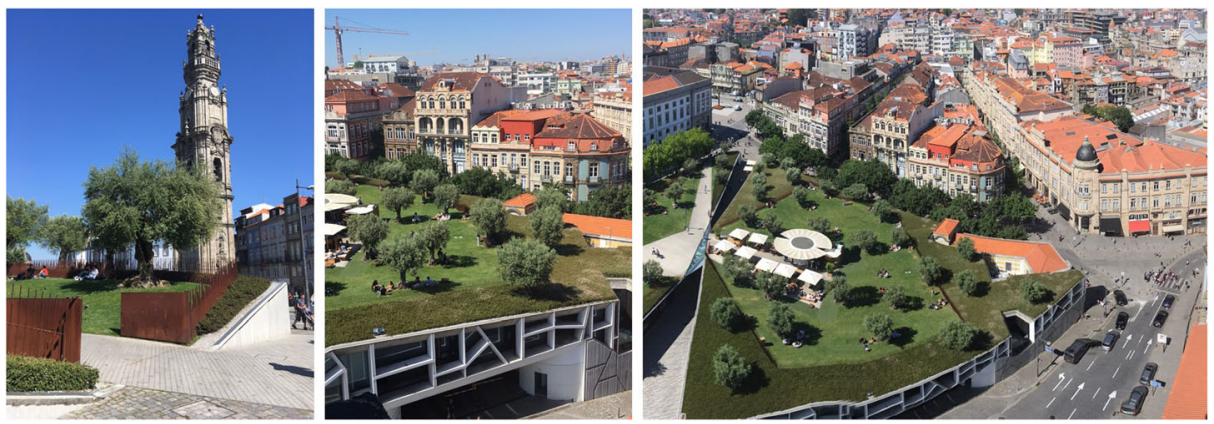

Fig. 3 Green roof located in Porto, Portugal, in the context of the building and city integration 
elements in the sense of how they benefit from each other, being thus possible to determine the optimum location for them. The inputs and outputs of the elements are considered so that a circular relationship is established;

- Each element performs several functions: identify, through functional analysis, as much as more functions as possible for each element, allowing for the maximization of the design efficiency;

- Each relevant function is supported by many elements: identify the critical functions of the system (e.g., water, food, energy), and ensure that they are supported in two or more ways. With this approach, a resilient design is set, and it is assured that critical functions will continue if an element from the system fails;

- Efficient energy planning: it is based on the principle of zones and sectors where placing the elements in a carefully planned way into the design will allow for an efficient energy use;

- Use of biological resources: aims at the use of biological resources (e.g., plants and animals) in a way oriented for energy and materials recycling, to determine the sustainability of the system;

- Energy cycling: it focuses on the promotion of cycling to increase the yield, through capturing, storing, and using energy and nutrients onsite and so to perpetuate life;

- Small scale intensive systems: the intention is to have systems managed with less resources, energy efficient, and at the same time reaching maximum productivity;

- Accelerating succession and evolution: using and accelerating natural plant succession to establish favorable sites and soils;

- Diversity: a productive and interactive system may be sustained by a polyculture and diversity of beneficial species. The focus is not on the number of different elements within the system but rather their functional connections. The stability of a system is not dictated by diversity but instead by multiple functions where the resources development is enhanced, and self-regulation is sustained;

- Edge effect: by taking advantage of the edge effect, it is possible to increase the productivity and yields of a system. This concept refers to a higher diversity that exists in the region where edges of two ecosystems overlap and share resources;

- Attitudinal principles: these principles are people-focused, related to the designer attitude towards the system being conceived, such as working with nature.

Reports are scarce related to the application of permaculture to green roofs, such as the roof top analysis that was undertaken (as an area for the development of permaculture design) in Shiraz in order to become a Garden City, through roof gardening [49]. However, for other NBS such as constructed wetlands, more detailed information is found, e.g., the work by Abrahams et al. [50], where a wetland was created for wastewater purification, biomass production, flood resilience, and biodiversity enhancement, and by Stefanakis $[51,52]$ where an industrial effluent is described for wastewater purification, effluent reuse in irrigation of commercial plants, and reed biomass exploitation for compost production and biogas production. Calheiros et al. [53] did not go deep into to the subject but highlighted the importance and contribution of permaculture when designing constructed wetland systems.

Overall, green roofs can be considered interfaces for energy and resource exchange between a constructed structure and the environment. They are integrated solutions that need an interdisciplinary framework [25]. 


\section{Green Roof Inclusion in Cities}

Human health and well-being are positively influenced by nature, as entailed in the biophilic concept that expresses the innate affinity that human beings have with nature. To bring nature into the city, actions must be taken, through the creation of more natural systems in the city sites and on the buildings (e.g., green roofs and façades). Singapore is an example that illustrates that densely populated cities, highly urbanized, are able to work with nature and take into consideration the biophilic urbanism [21]. This territory was able to achieve that, establishing a strong commitment to innovation in urban planning, where regulations and strategies were set [53]. Green roofs have been considered part of a green strategy to provide ecosystem services and also the best management practice to mitigate the adverse effects of urbanization and contribute to climate change adaptation and mitigation [25, 26, 29], although there are still constraints associated to the building life cycle process (i.e., planning and design), and the construction and operation and management stages [54]. For green roof inclusion in cities, it is thus important to (1) identify and overcome barriers, (2) set guidelines and standardization, (3) establish policies, incentives, and strategies, (4) leverage organizations delivering NBS services, and (5) promote awareness, dissemination, and investment in education. In more detail:

1. Identify and overcome barriers: the main barriers associated to the green roof installation have been highlighted by Li and Yeung [55]: (i) possibility to increase the costs concerning design, construction, and maintenance, (ii) lack of incentive from the government towards developers and owners of existing buildings, (iii) technical difficulties during the design and construction process, (iv) the age of existing building, (v) poor structural integrity of the building to deal with green roof loading, (vi) lack of awareness about green roofs in public and private sectors, and (vii) lack of promotion from the government side among the public and private sectors.

2. Guidelines and standardization: to build trust in green roof systems, it is important to guarantee a scientific knowledge-based approach and assurance of the best practices. Guidelines and standardization support the general principles and requirements for planning, design, execution, and maintenance aligned with the best practices. Several technical guides, guidelines, manuals, and codes for green roof implementation have been issued with general orientations or are focusing on a specific climate or country that allows for setting a platform for green roof inclusion in cities [23].

3. Establish policies, incentives, and strategies: The success of implementation and adoption of NBS, and in particular green roofs, will be dictated by the investment made on the policies, incentives, and strategies by the government. According to Ngan [56], green roof policies and incentives can fall into four categories: (i) direct financial incentives, (ii) indirect financial incentives, (iii) ecological compensation measures, and (iv) integration into development regulations. Strategies for green roof inclusion can be envisaged at a city or country scale or considering a broader scale, e.g., the European scale, with several programs and strategic directives launched by EU, as mentioned before [23].

4. Leverage organizations delivering NBS services: The adoption of NBS depends in part on the market development capacity of the sector to answer the actual challenges and on having the effective policy support measures in place. Besides that, with clear policies, incentives, and strategies, the market will be able to deliver the solutions to match the 
needs. Kooijman et al. [57] identified two types of organizations delivering NBS products and services: (i) nature-based enterprise (NBE), associated to an economic activity, and (ii) nature-based organization (NBO), not associated to economic activity. The main difference between them is that NBE "use nature as a core element of their product/ service offering for the planning, delivery, and/or stewardship of NBS and engage in economic activity" and NBO "use nature as a core element of their product/service offering for the planning, delivery, and/or stewardship of NBS but do not engage in economic activity." From their conclusions, there is a need of organizations that are able to deliver large-scale implementation of NBS and market development. Furthermore, the recognition of NBE as important actors to leverage NBS and to job creation is an important dimension for NBS inclusion in cities, which also applies in particular to green roof systems [57].

5. Promote awareness, dissemination, and invest in education: awareness and dissemination of green roofs is of outmost importance to deliver trust and knowledge about the technology, especially to inform about the benefits that have direct impact on the endusers or consumers and that will support afterwards the willingness to pay for this NBS. Furthermore, it is also important to show that besides the individual gains, there are also benefits for the community [58]. Concerning education about green roofs, there is an increasing need to integrate this thematic in the syllabus and curriculum of the schools and in higher education level, and also to make tools available for teachers to develop an interdisciplinary and creative approach. Hands-on examples will trigger the attention and the comprehension for this technology [59].

The main drivers to green roof implementation have been identified by Zhan and He [58] as policy pressure, market pressure, and innovation and technology. The way to include more green roofs in the cities thus encompasses the strengthening of green roof drivers, foster motivations, and overcome the identified barriers, through the involvement of the top players and stakeholders (e.g., designer, engineer, constructor and builder, contractor, building operator, owner, end-user, government agent) [58].

\section{Conclusions}

The way in which the occupation of the urban territory was developed and the cities were evolved, led to a disruption in natural flows and a series of problems associated to urban sprawl. Green infrastructures operate at different scales and rely on nature to generate environmental (e.g., conservation of biodiversity or adaptation to climate change), economic (e.g., job creation and property valuation), and social (e.g., water drainage) benefits. In addition, they play an important role in mitigating the effects of urbanization, aiming to strengthen urban ecosystems in order to be more resilient to the challenges of climate change, contributing to the transition to a low-carbon economy and circularity of urban metabolism. The change of territories involves the conversion of monofunctional areas to multifunctional areas, using nature-based solutions with the support, if necessary, of pre-existing grey infrastructures. The inclusion of green roofs in cities is an important NBS, which provides several ecosystem services that play a pivotal role in the Water-Energy-Materials-Food-Ecosystem nexus. With this approach, buildings shift from a static to a dynamic and interactive status with their surroundings and with the citizens. 
This paper delivers an overview on how green roofs could be part of the urban metabolism and spark a transformation towards circular and resilient cities (aligned with the UN and EU trends); having in consideration as mainstream strategy to rethink the positioning of stakeholders, decision-makers, enterprises, educational units, research centers, and involvement of the society to effectively take action. The needs to understand the social, economic, and environmental vulnerabilities to delineate strategic actions for resilience adapted to local necessities were also highlighted. A full systematic approach providing quantitative data on the cost-benefits of green roofs was not carried out, although this aspect is of relevance to have supportive data on green roof technology, and it would be of interest to address it in future publications.

Author Contribution Cristina S. C. Calheiros: Conceptualization, writing-original draft, review, and editing Alexandros I. Stefanakis: Conceptualization, writing, and review

Funding CSC Calheiros received the support of national funds through FCT - Foundation for Science and Technology within the scope of UIDB/04423/2020 and UIDP/04423/2020.

Data Availability Not applicable.

Code Availability Not applicable.

\section{Declarations}

Competing Interests The authors declare no competing interests.

\section{References}

1. United Nations (2019) World urbanization prospects: the 2018 revision (ST/ESA/SER.A/420). Department of Economic and Social Affairs, Population Division. New York: United Nations. ISBN: 978-92-1-1483192

2. Vandecasteele I, Baranzelli C, Siragusa A, Aurambout JP (Eds.), Alberti V, et al. (2019) The future of cities - opportunities, challenges and the way forward, EUR 29752 EN, Publications Office, Luxembourg.

3. Elmqvist T, Zipperer WC, Güneralp B (2015) Chapter 10: urbanization, habitat loss and biodiversity decline: solution pathways to break the cycle. In: Seto K, Solecki W, \& Griffith C (Eds.), The Routledge Handbook of Urbanization and Global Environmental Change (1st ed.), Routledge. https://doi.org/10.4324/ 9781315849256

4. Scalenghe R, Marsan FA (2009) The anthropogenic sealing of soils in urban areas. Landsc Urban Plan 90(1-2):1-10. https://doi.org/10.1016/j.landurbplan.2008.10.011

5. Noll M (2020) Draft proposal for a European partnership under Horizon Europe Driving Urban Transitions to a sustainable future (DUT). Version 25 May 2020. Accessed in: 26/01/2021. Accessed at: https://jpiurbaneurope.eu/wp-content/uploads/2020/06/Driving-Urban-Transitions_Partnership_FinalDraft.pdf

6. EC (European Commission) (2021) Press release: new European Bauhaus: commission launches design phase. Brussels, 18 January 2021 Accessed in: 26/01/2021. Accessed at: https:/ec.europa.eu/commission/ presscorner/api/files/document/print/en/ip_21_111/IP_21_111_EN.pdf

7. ICLEI (2019) Resilient cities, thriving cities: the evolution of urban resilience. ICLEI - Local Governments for Sustainability e.V. Bonn, Germany. Accessed in: 26/01/2021. Accessed at: https://e-lib.iclei.org/ publications/Resilient-Cities-Thriving-Cities_The-Evolution-of-Urban-Resilience.pdf

8. Gravagnuolo A, Angrisano M, Girard LF (2019) Circular economy strategies in eight historic port cities: criteria and indicators towards a circular city assessment framework. Sustainability 11:3512. https://doi.org/ $10.3390 /$ su1 1133512 
9. Restrepo JDC, Morales-Pinzón T (2018) Urban metabolism and sustainability: precedents, genesis and research perspectives. Resour Conserv Recycl 131:216-224. https://doi.org/10.1016/j.resconrec.2017.12. 023

10. Mangialardo A, Micelli E (2018) Rethinking the construction industry under the circular economy: principles and case studies. In: Bisello A, Vettorato D, Laconte P, Costa S (eds) Smart and sustainable planning for cities and regions. Green Energy and Technology, Springer, Cham, pp 333-344. https://doi. org/10.1007/978-3-319-75774-2_23

11. Pearlmutter D, Theochari D, Nehls T, Pinho P, Piro P, Korolova A, Papaefthimiou S, Mateo CG, Calheiros, Zluwa I, Pitha U, Schosseler P, Florentin Y, Ouannou S, Gal E, Aicher A, Arnold K, Igondová E, Pucher B (2020) Enhancing the circular economy with nature-based solutions in the built urban environment: green building materials, systems and sites. Blue-Green Systems 2(1):46-72. https://doi.org/10.2166/bgs.2019.928

12. United Nations (2017) New urban agenda. General Assembly. Resolution adopted by the General Assembly on 23 December 2016. A/RES/71/256 Accessed in: 26/01/2021. Accessed at: https://www.un.org/en/ development/desa/population/migration/generalassembly/docs/globalcompact/A_RES_71_256.pdf

13. McDonald R, Giineralp B, Zipperer W, Marcotullio PJ (2014) The future of global urbanization and the environment. Solut J 5(6):60-69

14. Stefanakis AI, Calheiros CSC, Nikolaou I (2021) Nature-based solutions as a tool in the new circular economic model for climate change adaptation. Circular Economy and Sustainability, in press.

15. EC (European Commission) (2015) Nature-based solutions and re-naturing cities. Final Report. DirectorateGeneral for Research and Innovation. Climate Action, Environment, Resource Efficiency and Raw Materials. ISBN 978-92-79-46051-7. https://doi.org/10.2777/765301

16. UN (2019) NBS for Climate Coalition. The nature-based solutions for climate manifesto; UN Climate Action Summit. Accessed in: 26/01/2021. Accessed at: www.unenvironment.org/nature-basedsolutions-climate

17. EC (European Commission) (2019) The European green deal. COM/2019/640 Final. Communication from the Commission to the European Parliament, the European Council, the Council, the European Economic and Social Committee and the Committee of the Regions. Brussels. Accessed in: 26/01/2021. Accessed at: https://eur-lex.europa.eu/legal-content/EN/TXT/?uri=COM:2019:640:FIN

18. COST (European Cooperation in Science and Technology) Action CA17133 (2018) Memorandum of understanding for the implementation of the COST action 'Implementing nature based solutions for creating a resourceful circular city’ (Circular City Re.Solution) CA17133; COST 044/18. Brussels, Belgium. Accessed in: 26/01/2021. Accessed at: https://e-services.cost.eu/files/domain_files/CA/Action_CA17133/ mou/CA17133-e.pdf

19. EC (European Commission) (2019) Brussels, 24.5.2019 SWD, 193 final. Commission staff working document. Guidance on a strategic framework for further supporting the deployment of EU-level green and blue infrastructure Accessed in: 26/01/2021. Accessed at: https://ec.europa.eu/transparency/regdoc/rep/ 10102/2019/EN/SWD-2019-193-F1-EN-MAIN-PART-1.PDF

20. Armour T, Armour S, Hargrave J, Revell T (2014) Cities alive: rethinking green infrastructure. ARUP. Accessed in: 26/01/2021, at: https:/www.arup.com/perspectives/publications/research/section/cities-aliverethinking-green-infrastructure

21. Stefanakis AI (2019) The role of constructed wetlands as green infrastructure for sustainable urban water management. Sustainability 11(24):6981. https://doi.org/10.3390/su11246981

22. Liu H, Jia Y, Niu C (2017) “Sponge City" concept helps solve China's urban water problems. Environ Earth Sci 76:473. https://doi.org/10.1007/s12665-017-6652-3

23. Calheiros CSC, Castiglione B, Palha P (2021) Nature-based solutions for social and environmental responsible new cities: the contribution of green roofs. In: Stefanakis AI, Nikolaou I (eds.), Circular Economy and Sustainability, Volume 2, Elsevier Publishing

24. Sutton RK (2014) Aesthetics for green roofs and green walls. Landscape Architecture Program: Faculty Scholarly and Creative Activity. J Living Archit 19 http://digitalcommons.unl.edu/arch land_facultyschol/19

25. Sutton RK, Lambrinos J (2015) Green roof ecosystems: summary and synthesis. In: Sutton R. (ed.), Green roof ecosystems. Ecological Studies (Analysis and Synthesis), Vol 223. Springer, Cham. https://doi.org/10. 1007/978-3-319-14983-7 17

26. Shafique M, Kim R, Rafiq M (2018) Green roof benefits, opportunities and challenges - a review. Renewable and Sustainable. Energy Rev 90:757-773

27. Jim CY (2017) Green roof evolution through exemplars: germinal prototypes to modern variants. Sustain Cities Soc 35:69-82. https://doi.org/10.1016/j.scs.2017.08.001 
28. ANCV (Edt) (2019) Coberturas Verdes: Guia Técnico para projeto, construção e manutenção. ANCVAssociação Nacional de Coberturas Verdes. ISBN: 9789893300298

29. Vijayaraghavan K (2016) Green roofs: a critical review on the role of components, benefits, limitations and trends. Renew Sust Energ Rev 57:740-752. https://doi.org/10.1016/j.rser.2015.12.119

30. Nash C, Clough J, Gedge D, Lindsay R, Newport D, Ciupala MA, Connop S (2015) Initial insights on the biodiversity potential of biosolar roofs: a London Olympic Park green roof case study. Isr J Ecol Evol 62: 74-87. https://doi.org/10.1080/15659801.2015.1045791

31. Chemisana D, Lamnatou C (2014) Photovoltaic-green roofs: an experimental evaluation of system performance. Appl Energy 119:246-256. https://doi.org/10.1016/j.apenergy.2013.12.027

32. Andenæs E, Kvande T, Muthanna TM, Lohne J (2018) Performance of blue-green roofs in cold climates: a scoping review. Buildings 8(4):55. https://doi.org/10.3390/buildings 8040055

33. GRO-Green Roof Organisation (2014) The GRO green roof code. Published by Groundwork Sheffield. ISBN: 978-9568378-1-3

34. Torrance S, Bass B, MacIvor S, McGlade T (2013) City of Toronto: design guidelines for biodiverse green roofs. www.toronto.ca/greenroofs

35. Walters SA, Midden KS (2018) Sustainability of urban agriculture: vegetable production on green roofs. Agric Rev 8:168. https://doi.org/10.3390/agriculture8110168

36. Tadeu A, Simões N, Almeida R, Manuel C (2019) Drainage and water storage capacity of insulation cork board applied as a layer on green roofs. Constr Build Mater 209:52-65

37. Stovin,V (2010) The potential of green roofs to manage urban stormwater. Water and Environment Journal 24:192-199. https://doi.org/10.1111/j.1747-6593.2009.00174.x

38. Kelly MJ (2009) Retrofitting the existing UK building stock. Build Res Inf 37(2):196-200. https://doi.org/ $10.1080 / 09613210802645924$

39. Saiz S, Kennedy C, Bass B, Pressnail K (2006) Comparative life cycle assessment of standard and green roofs. Environ Sci Technol 40(13):4312-4316. https://doi.org/10.1021/es0517522

40. Wilkinson S, Dixon T (2016) Green roof retrofit: building urban resilience. John Wiley \& Sons, Online

41. EC (European Commission) (2020) A new circular economy action plan for a cleaner and more competitive Europe. COM (2020) 98 final. Communication from the Commission to the European Parliament, The Council, The European Economic and Social Committee and the Committee of the Regions. Brussels. Accessed in: 26/01/2021. Accessed at: https://eur-lex.europa.eu/legal-content/EN/TXT/PDF/?uri=CELEX: 52020DC0098\&from=EN

42. Cristiano E, Deidda R, Viola F (2021) The role of green roofs in urban Water-Energy-Food-Ecosystem nexus: a review. Sci Total Environ 756:143876. https://doi.org/10.1016/j.scitotenv.2020.143876

43. Miller C, et al. (2016) Extensive vegetative roofs. Accessed in: 26/01/2021. Accessed at: https://www.wbdg. org/resources/extensive-vegetative-roofs

44. Wong NH, Tay SF, Wong R, Ong CL, Sia A (2003) Life cycle cost analysis of rooftop gardens in Singapore. Build Environ 38(3):499-509. https://doi.org/10.1016/S0360-1323(02)00131-2

45. Köhler M, Poll PH (2010) Long-term performance of selected old Berlin green roofs in comparison to younger extensive green roofs in Berlin. Ecol Eng 36:722-729

46. Khan MM, Akram MT, Janke R, Qadri RWK, Al-Sadi AM, Farooque AA (2020) Urban horticulture for food secure cities through and beyond COVID-19. Rev Sustain 12:9592. https://doi.org/10.3390/ su12229592

47. Mollison B (2002) Permaculture: a designers' manual, second edition. Tagari Publications. Tasmania, Australia

48. Mollison B, Sla RM (2000) Introduction to permaculture. second edition. Tagari Publications. Tasmania, Australia

49. Fattahi S, Bazrkar M (2013) Garden city to city in a garden-case study: Shiraz City as a "permaculture" Model in Iran. Proceedings of the 49th ISOCARP Congress Brisbane, Australia, 1-4 October 2013, pp 410-420

50. Abrahams JC, Coupe SJ, Sañudo-Fontaneda LA, Schmutz U (2017) The Brookside Farm Wetland Ecosystem Treatment (WET) system: a low-energy methodology for sewage purification, biomass production (yield), flood resilience and biodiversity enhancement. Sustainability 9:147. https://doi.org/10.3390/ su9010147

51. Stefanakis AI (2020) Constructed wetlands for sustainable wastewater treatment in hot and arid climates: opportunities, challenges and case studies in the Middle East. Water 12(6):1665. https://doi.org/10.3390/ w12061665

52. Stefanakis AI (2020) A circular model for sustainable produced water management in the oil and gas industry. In: Stefanakis AI, Nikolaou I (eds) Circular economy and sustainability. Elsevier Publishing, Volume II 
53. Calheiros CSC, Almeida CMR, Mucha AM (2018) Chapter 8. Multiservices and functions of constructed wetlands. In: Halicki W (ed) Wetland function, services, importance and threats. Nova Science Publishers, Inc. New York, pp 269-298

54. Newman P (2014) Biophilic urbanism: a case study on Singapore. Australian Planner 51(1):47-65. https:// doi.org/10.1080/07293682.2013.790832

55. Li WC, Yeun KKA (2014) A comprehensive study of green roof performance from environmental perspective (review article). Int J Sustain Built Environ 3:127-134. https://doi.org/10.1016/j.ijsbe. 2014.05.001

56. Ngan G (2004) Green roof policies: tools for encouraging sustainable design. Accessed in: 26/01/2021, at: http://www.gnla.ca/assets/Policy\%20report.pdf

57. Kooijman ED, McQuaid S, Rhodes M-L, Collier MJ, Pill F (2021) Innovating with nature: from naturebased solutions to nature-based enterprises. Sustainability 13:1263. https://doi.org/10.3390/su13031263

58. Zhang G, He B (2021) Towards green roof implementation: drivers, motivations, barriers and recommendations. Urban For Urban Green 58:126992. https://doi.org/10.1016/j.ufug.2021.126992

59. Calheiros CSC, Calafate L, Vasconcelos ML, Cardoso A, Vasconcelos C (2019) Chapter 4. Education for sustainability through conceptual modelling: green roofs as a way of integrating buildings and nature. In: R.V. Nata (ed.), Progress in education, Volume 57. Nova Science Publishers, Inc, New York, p. 135-168 